\section{Early 'fibre-optic' light}

By Brian Williams, retired GDP, museum volunteer and Honorary Secretary of the Lindsay Society: the History of Dentistry

Cameron's Transillumination Diagnostoset was launched in 1922, the year William John Cameron (1879 to 1953) changed the name of his American Surgical Specialty Company, founded 1 August 1915 in Chicago, to Cameron's Surgical Specialty Company.

Its wooden box houses seven whitenedglass probes of various sizes and shapes. They are vacuum sealed with a tiny filament and reflector within the tip. They were not fibre optics as we understand the term today but more a device that allowed light from the aptly named Surgilite to be directed safely on inaccessible parts of the mouth when wisdom teeth were being removed.

Moving the slide along the body of the Vitrohm adjuster varied the intensity of the light filament in the glass tube.

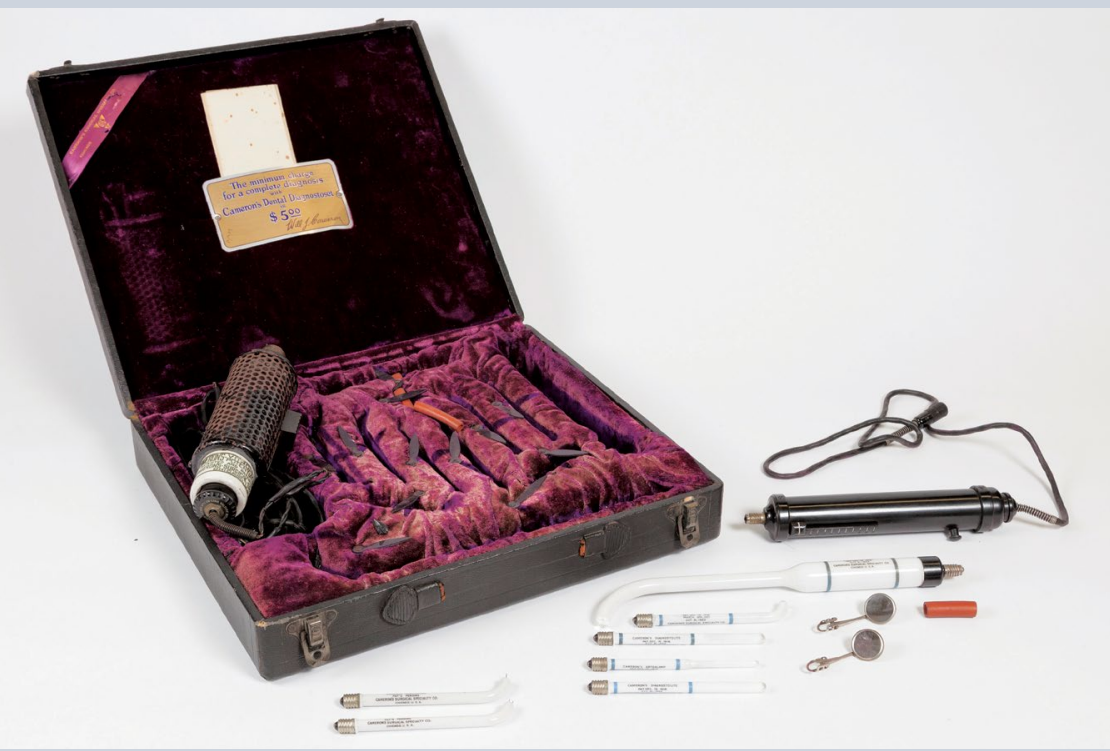

Two of the tubes were modified to have two short bare wires protruding from the tips. These special probes were attached to the Vitalitester and acted as electric pulp testers. The shock is administered by depressing the button on the side of the Vitalitester and its intensity was modified by another sliding scale.

By shining the intense light through tissues (transillumination) the Diagnostoset became a diagnostic tool for - it was claimed - identifying cracked teeth and soft-tissue tumours. 